\title{
Do overweight youngsters like food more than lean peers? Assessing their implicit attitudes with a personalized Implicit Association Task
}

\author{
Mietje Craeynest ${ }^{\mathrm{a}, \mathrm{c}}$, Geert Crombez ${ }^{\mathrm{a}, \mathrm{c}}$, Leen Haerens ${ }^{\mathrm{b}}$, Ilse De Bourdeaudhuij ${ }^{\mathrm{b}, \mathrm{c}, *}$ \\ ${ }^{a}$ Department of Experimental Clinical and Health Psychology, Ghent University, Henri Dunantlaan 2, B-9000 Ghent, Belgium \\ ${ }^{\mathrm{b}}$ Department of Movement and Sports Sciences, Ghent University, Watersportlaan 2, B-9000 Ghent, Belgium \\ ${ }^{\mathrm{c}}$ Institute for Psychology and Health, The Netherlands
}

Received 27 June 2006; received in revised form 22 May 2007; accepted 23 May 2007

Available online 2 June 2007

\begin{abstract}
It has been theorized that overweight and obesity are related with a heightened (unhealthy) food preference. Until now both selfreports and indirect attitude measures offer little support for this hypothesis. Using a personalized version of the Implicit Association Task [IAT; Greenwald, A. G., McGhee, D. E., \& Schwartz, J. L. (1998). Measuring individual differences in implicit cognition: The Implicit Association Test. Journal of Personality and Social Psychology, 74, 1464-1480], this study investigated (1) whether overweight youngsters $(n=40)$ implicitly prefer palatable food to an attractive non-food category such as hobbies and (2) whether they implicitly prefer unhealthy palatable food to healthy palatable food, compared to a matched group of lean controls $(n=40)$. Further, it was examined whether these implicit attitudes correlated with self-reported food and hobby attitudes. The results revealed no effect for food versus hobbies. Both groups implicitly preferred healthy to unhealthy food. Positive correlations between implicit and self-reported attitudes were only found for hobbies. Several interpretations of these findings are discussed.
\end{abstract}

(C) 2007 Elsevier Ltd. All rights reserved.

Keywords: Overweight; Youngsters; Implicit; Attitude; Food; IAT

\section{Introduction}

It is generally acknowledged that overweight and obesity in youngsters is a serious and prevalent problem (Dietz \& Robinson, 2005; Lissau et al., 2004). Apart from genetic factors (Farooqi, 2005) and reduced physical activity (Fox, 2004), the epidemic has been blamed on excessive fat, sugar and protein intake (McGloin et al., 2002; Nicklas, Yang, Baranowski, Zakeri, \& Berenson, 2003).

One of the possible determinants underlying this food pattern may be that overweight and obese youngsters have

\footnotetext{
${ }^{*}$ Corresponding author. Address: Department of Movement and Sports Sciences, Ghent University, Watersportlaan 2, B-9000 Ghent, Belgium. Tel.: +329 264 36; fax: +32 92646484 . huij).

E-mail address: Ilse.DeBourdeaudhuij@UGent.be (I. De Bourdeaud-
}

more positive attitudes towards unhealthy palatable food than lean counterparts. Indeed, several studies investigating taste preference showed that obese people have an enhanced liking for calorically dense food (Capaldi, 1996; Drewnowski, Kurth, Holden-Wiltse, \& Saari, 1992; Reed, Bachmanov, Beauchamp, Tordoff, \& Price, 1997). However, studies using self-reports to assess food preferences often have led to conflicting findings. Some studies have shown that attitudes indeed explain a reasonable amount of the eating behaviour (e.g., Dennison \& Shepherd, 1995). Others revealed that youngsters with obesity are less positive towards unhealthy food than lean controls (e.g., Perl, Mandic, Primorac, Klapec, \& Perl, 1998).

According to Greenwald et al. (2002), self-reports may be sometimes limited in their predictive and explanatory value because of two reasons: First, as they are completed under conscious control, they may be influenced by 
self-presentation strategies. Second, participants may have limited introspective knowledge of the processes underlying their behaviour. According to Fazio's (1990) MODE model, which is an acronym for Motivation and Opportunity as DEterminants, behaviour may be driven by automatic and spontaneous processes that occur beyond conscious reflection. More specifically, when a person is not motivated or has no opportunity (e.g., time) to consider the benefits and the barriers to perform a behaviour, behaviour may be guided by implicit attitudes, which can be defined as the immediate, automatic affective reactions that stimuli evoke. This kind of attitudes are best assessed indirectly, for instance using response time based measures (Fazio \& Olson, 2003). Conversely, when there is motivation or opportunity for deliberation, behaviour will be guided by conscious and well-considered or explicit attitudes that may be easily tapped by direct measures which permit cognitive reflection, such as self-reports.

There has been an increase in the application of indirect measures in health psychology (e.g., Roefs \& Jansen, 2002; Swanson, Rudman, \& Greenwald, 2001; Wiers, van Woerden, Smulders, \& Jong, 2002). One of the most-used indirect measures is the Implicit Association Task (IAT), developed by Greenwald, McGhee, and Schwartz (1998). The IAT is a response time based computer task, in which stimuli have to be sorted according to one of four categories. More specifically, there are two target categories (which are concepts, e.g. flowers and insects, of which a certain characteristic can be assessed such as their valence) and two attribute categories (which represent a certain characteristic that has to be assessed, such as valence that may be operationalized by e.g. positive and negative nouns). Sorting has to be done as fast and as accurately as possible, by pressing on one of two different response keys. Each response key is attributed to one target and one attribute category. The task presumes that, when the same response is used for targets and attributes that are associated in memory (e.g., flowers and positive versus insects and negative), response time is faster than when the same response is used for targets and attributes that are unrelated (e.g., flowers and negative versus insects and positive). This pattern of response facilitation is thought to reflect implicit, automatic processing.

Roefs and Jansen (2002) used an IAT to investigate whether adults with obesity implicitly prefer high-fat food towards low-fat food, compared to a normal-weight control group. Consistent with a social desirability hypothesis, both groups reported negative explicit attitudes towards high-fat food on a questionnaire. However, in contrast with their expectations, they found that both groups had also negative implicit attitudes towards high-fat food, with the obesity group having even more negative attitudes than the controls. In line with Karpinski and Hilton (2001), this unexpected finding may be owing to the nature of the IAT, because the category labels 'high-fat food' versus 'low-fat food' and 'positive' and 'negative' remained clearly on the screen during the test. As in Western society words such as 'low-fat' and 'high-fat' are strongly associated with a positive and negative valence respectively, it is not inconceivable that Roefs and Jansen (2002) assessed these Western societal views instead of the personal implicit attitudes towards high-fat and low-fat food.

One way to circumvent this label effect, is to use an alternative indirect measure in which the labels 'high-fat' and 'low-fat' do not have to be used, such as the Extrinsic Affective Simon Task (EAST; for an extended description of this task, we refer to De Houwer, 2003). In a former study, we used this task and hypothesised that children with obesity would implicitly like unhealthy food more than healthy food in comparison with lean controls (Craeynest et al., 2005). Using a rating scale, we also assessed their explicit attitudes. The results revealed that both groups had positive explicit attitudes towards both healthy and unhealthy food. Interestingly, a borderline significant effect showed that children with obesity implicitly liked both unhealthy and healthy food, whereas the controls had neutral attitudes. This could indicate that children with obesity not just prefer unhealthy food, but simply like eating. Moreover, it seems that the liking of food in the obesity group is more automatic than in the control group, as the latter had positive attitudes on the self-reports, but not when these attitudes were assessed indirectly. It would be worthwhile to further explore this idea by using an indirect measure in which the attitude towards food is compared with the attitude towards alternative stimuli of which children have reported that they like them, such as toys (Schwartz, Chen, \& Brownell, 2003). For youngsters and adolescents, attractive non-food may be their hobbies.

Another possibility to avoid the societal view contamination is to use an adapted version of the IAT that should reduce the extrapersonal influences. Olson and Fazio (2004) proposed a 'personalized IAT' that differed from the traditional IAT on two factors. First, because the labels 'positive' and 'negative' of the traditional IAT could carry a normative implication, they are respectively changed into 'I like' and 'I dislike' in the personalized IAT. Second, in contrast to the traditional IAT where a red cross appeared on the screen for a wrong response, the personalized IAT provides no error feedback. Interestingly, the personalized IAT showed good validity in the context of food preferences. For instance, Olson and Fazio (2004, Experiment 3) found that a traditional IAT revealed a preference for apples to candy in normal-weights (replicating Karpinski \& Hilton, 2001), whereas a personalized IAT showed - in line with behaviour measures - no clear preference for apples over candy. Further, the personalized IAT has also successfully assessed implicit attitudes in more social sensitive domains such as smoking. More specifically, De Houwer, Custers, and De Clercq (2006, Experiment 2) found that smokers had implicit positive attitudes towards smoking on a personalized IAT, whereas Swanson et al. (2001) earlier found that smokers had negative implicit attitudes towards smoking on a traditional IAT. 
The aim of this study was to extend the findings of Craeynest et al. (2005) in overweight and lean youngsters using a personalized IAT. More specifically, it was investigated whether overweight youngsters - in contrast to lean controls - implicitly prefer food when they have to choose between palatable food and hobbies that they really like on an explicit level. Further, it was examined whether a personalized IAT would reveal a stronger preference for palatable unhealthy food over palatable healthy food in overweight youngsters than in lean controls. Self-reported attitudes were measured in order to investigate whether they correlate with the implicit attitudes.

\section{Methods}

\subsection{Participants}

Forty youngsters with overweight (mean $\mathrm{ABMI}^{1}=$ $137.45, \mathrm{SD}=18.12 ; 11$ boys; age $M=14.83, \mathrm{SD}=0.75$; range 13-16 yo) and forty normal-weight youngsters (mean $\mathrm{ABMI}=98.04, \mathrm{SD}=8.87 ; 11$ boys; age $M=14.83, \mathrm{SD}=$ 0.64 ; range 14-16 yo) participated in the study. According to Cole, Bellizzi, Flegal, and Dietz (2000), 30 youngsters of the overweight group could be categorized as overweight, and 10 youngsters as obese. In the following, they are taken together as the overweight group. Both the overweight and the control group did not differ in age, $t<1$, and in sex and educational level, all $\chi^{2} \mathrm{~s}<1$.

\subsection{Materials}

\subsubsection{Personalized Implicit Association Task}

All youngsters carried out two personalized IATs that differed with respect to the targets. The first task assessed the implicit attitudes towards palatable food versus hobbies; in the second task the implicit attitudes towards palatable healthy versus palatable unhealthy food were tested. In the food/hobby IAT, targets were six individually selected palatable food articles (e.g., pancakes) and six individually selected hobbies that the participant liked (e.g., play station). In the healthy/unhealthy food IAT, targets were six individually selected palatable healthy food articles (e.g., fruit salad) and six individually selected palatable unhealthy food articles (e.g., chocolate). The reason for this idiosyncratic target stimuli selection was to obtain stimuli that were for each individual participant personally attractive. In both tasks, attributes were six positive nouns

\footnotetext{
${ }^{1}$ The Body Mass Index (BMI; weight $/$ height $^{2} ; \mathrm{kg} / \mathrm{m}^{2}$ ) is accepted as a reliable and valid index of relative adiposity. However, as mean normal values of BMI vary substantially with age and values for individuals of different ages are difficult to compare, an adjusted BMI (ABMI) was used. ABMI was calculated using the formula (actual BMI/ideal BMI [50th percentile for same sex and age]) $\times 100$ (Valverde, Patin, Oliveira, Lopez, $\&$ Vitolo, 1998). The 50th percentiles were derived from Flemish growth reference charts. An ABMI of $100 \%$ is considered ideal.
}

(e.g., smile) and six negative nouns (e.g., dead). All attribute stimuli were selected from Hermans and De Houwer (1994), following the criterion that for each positive noun, a negative noun was chosen with an equal amount of syllables. Attributes and some examples of the target stimuli are presented in Appendix.

The IATs were run on an IBM compatible Pentium IV computer with a $15 \mathrm{in}$. colour screen using Inquisit 1.33 software, which measures reaction times (RTs) with millisecond accuracy (De Clercq, Crombez, Buysse, \& Roeyers, 2003). On each trial, participants were instructed to classify as quickly and as accurately as possible the stimulus word. In the food/hobby task, the category labels were 'food', 'hobby', 'I like' and 'I dislike'. In the healthy/unhealthy food IAT, the category labels were 'healthy food', 'unhealthy food', 'I like' and 'I dislike'. The respective category labels were presented in the left and right top corner of the screen and remained there throughout the task. Participants responded to the categorization task by pressing either the ' $a$ ' key with the left index finger or the 'p' key with the right index finger on an AZERTY keyboard. Each stimulus was presented in white in the centre of a black screen. Letters were $7 \mathrm{~mm}$ high and $5 \mathrm{~mm}$ wide.

\subsubsection{Self-reports}

Self-report attitude measures assessed the attitudes towards the individual target stimuli and towards the categories. First, the youngsters had to write down the attribute stimuli they had selected, and rated it on a 7-point scale, ranging from 'I don't like it at all' (-3) to 'I like it a lot' $(+3)$. Next, participants were asked to indicate on two 7point scales ranging from 'totally disagree' $(-3)$ to 'totally agree' $(+3)$, to what extent they liked both categories of the respective IAT (e.g., food and hobbies). Finally, one question assessed the relative attitude towards both categories of the respective IAT, using a 7-point scale ranging from the one category ( -3 ; e.g., 'food') till the other $(+3$; e.g., 'hobby'), whereby the scale numbers were not visible for the participants.

\subsection{Procedure}

The study was approved by the Ethical Committee of Ghent University. Pupils from four different schools were tested. In total, 12 class groups were selected based on their size and on the percentage of overweight youngsters. In order to avoid stigmatization of the overweight group, the whole class was tested at once in the school's computer class room. As such, in total 208 children participated in this study. From this pool, we selected for each overweight participant a control participant, based on the match of school, educational level, sex, age and the condition of the IATs (that is explained further in this method section). The body mass index (BMI) was measured in a concurrent study investigating food and physical activity behaviour (Haerens et al., 2006). Each session started with a short introduction, telling the pupils that we wanted to 
investigate what youngsters like, followed by signing the informed consent. Next, they completed in a fixed order the food/hobby IAT, the questionnaire assessing their attitudes towards food and hobbies, the healthy/unhealthy food IAT and the questionnaire assessing their attitudes towards healthy and unhealthy food. Before conducting the food/hobby IAT, the youngsters were asked to mark six food articles that they really liked to eat in a list with 30 food articles, and to mark six hobbies that they really liked to do in a list with thirty hobbies. Before conducting the healthy/unhealthy food IAT, the youngsters had to mark six palatable healthy food articles that they really liked in a list with 28 healthy food articles, and six palatable unhealthy food articles that they really liked in a list with 28 unhealthy food articles. The participants were encouraged to generate other words when the lists did not suffice. The reason for the fixed order of the IATs was to avoid that the youngsters would be too much focussed on the importance of health in their choice of the food stimuli in the food/hobby IAT.

Each IAT started with a block in which the participant had to fill in the chosen target stimuli, followed by seven blocks of trials: (1) a practice block with attribute stimuli only (I like versus I dislike); (2) a practice block with target stimuli only (e.g., food versus hobby); (3) a critical combined block with all stimuli (e.g., food + I like versus hobby + I dislike); (4) repeat of Block 3; (5) a practice block with target stimuli only but with a reversal of the response key assignments; (6) a critical combined block with all stimuli, using the reversed key assignments of Block 5 (e.g., food + I dislike versus hobby + I like); (7) the same as Block 6. The order in which participants performed the mixed categorization blocks (e.g., Blocks 3-4 and 6-7) as well as the key that was assigned to the attribute stimuli (e.g., press 'a' for I like versus press 'p' for I dislike) was counterbalanced, resulting in four different conditions. Each practice block consisted of 24 trials (each attribute or target stimulus twice) and each critical block had 48 trials (each attribute and target stimulus twice). Stimuli were always presented in a random order, with an inter-trial interval of $400 \mathrm{~ms}$. According to Olson and Fazio (2004), no error feedback was given.

\section{Results}

\subsection{Personalized Implicit Association Task}

IAT scores were calculated using D600 measures, which is an optimized scoring algorithm proposed by Greenwald, Nosek, and Banaji (2003). Nevertheless, the same effects were found when we analysed the conventional measure (Greenwald et al., 1998). IAT-effects are based on the difference between the performance on both pairings (e.g., mean reaction time on food $+\mathrm{I}$ dislike minus mean reaction time on food + I like). For reasons of clarity, they are reported in milliseconds. On the food/hobby IAT, positive scores indicate stronger associations between food and
I like (versus hobby and I dislike), than between food and I dislike (versus hobby and I like); Positive scores on the healthy/unhealthy food IAT indicate stronger associations between unhealthy food and I like (versus healthy food and I dislike) than between unhealthy food and I dislike (versus healthy food and I like).

Initial analyses showed no effects of condition, all $F_{\mathrm{S}}<$ 1.35, age, all $F_{\mathrm{s}}<1.82$, sex, all $F_{\mathrm{s}}<1$, school, all $F_{\mathrm{s}}<1$, educational level, all $F_{\mathrm{s}}<1$, and BMI classification according to Cole et al. (2000, normal-weight versus overweight versus obese), all $F_{\mathrm{s}}<1.24$. Therefore, we ignored these variables in further analyses and used a Repeated Measures ANOVA with group (overweight versus normal-weight youngsters) and IAT task (food/hobby versus healthy/ unhealthy food) as independent variables and the D600 IAT scores as dependent variable. Eta squared $\left(\eta^{2}\right)$ is reported as an estimate of effect size. An $\eta^{2}$ of $0.20,0.50$ and 0.80 was used as a threshold to define small, medium and large effects, respectively.

The results only revealed a main effect of task, $F(1,78)=148.77, p<0.001, \eta^{2}=0.66$. No main effect of group, $F(1,78)=0.76$, ns, or an interaction effect of group and task were found, $F(1,78)=0.35$, ns. An additional one sample $t$-test showed that the IAT-effect differed significantly from zero on the healthy/unhealthy task, $t(79)=$ $17.94, p<0.001, \eta^{2}=0.80$, indicating that both groups preferred palatable healthy food to palatable unhealthy food. On the food/hobby task, the IAT-effect seemed positive for the overweight group and neutral for the control group, but a one sample $t$-test showed that they did not differ from zero, $t(79)=0.13$, ns. These findings indicated that both groups liked food in general to the same amount as their hobbies. All means of the food/hobby task are described in Table 1; all means of the healthy/unhealthy task are presented in Table 2. Post hoc independent $t$-tests revealed that both groups selected the same amount of unhealthy food (overweight: $M=21.62 \%, \quad \mathrm{SD}=3.42 \%$; normalweight: $M=23.11 \%, \mathrm{SD}=3.65 \%), t(78)=0.58, \mathrm{~ns}$, and passive hobbies (overweight: $M=22.63 \%, \mathrm{SD}=3.58 \%$; normal-weight: $M=19.08 \%, \mathrm{SD}=3.02 \%), t(78)=1.07$, ns, as targets for the food/hobby IAT.

\subsection{Self-reports}

\subsubsection{Self-reported attitudes}

A MANOVA with group as fixed factor and the selfreported attitudes towards food, hobbies, healthy food and unhealthy food as dependent variables showed no multivariate effect, $F(10,68)=1.04$, ns. Also no univariate effects of group were found on the mean attitude towards the selected IAT food items, $F(1,77)=0.63$, ns, towards the selected IAT hobby items, $F(1,77)=0.46$, ns, towards the selected IAT healthy food items, $F(1,77)=23$, ns, and towards the selected IAT unhealthy food attitudes, $F(1$, $77)=0.12$, ns. This indicated that both groups explicitly liked all food, hobby, healthy food and unhealthy food stimuli they had selected for the respective IATs to the 
Table 1

Means (M), Standard deviations (SD), Cronbach's $\alpha$ and Pearson correlations $(r)$ between implicit and self-reported food versus hobby attitudes and behaviour in overweight $(n=40)$ and normal-weight $(n=40)$ youngsters

\begin{tabular}{|c|c|c|c|c|c|c|c|c|c|c|}
\hline & \multicolumn{4}{|c|}{ Group } & \multirow[t]{3}{*}{$\alpha$} & \multirow[t]{3}{*}{2} & \multirow[t]{3}{*}{3} & \multirow[t]{3}{*}{4} & \multirow[t]{3}{*}{5} & \multirow[t]{3}{*}{6} \\
\hline & \multicolumn{2}{|c|}{ Overweight } & \multicolumn{2}{|c|}{ Normal-weight } & & & & & & \\
\hline & $M$ & SD & $M$ & SD & & & & & & \\
\hline 2. Mean attitude towards food items & 2.35 & 0.40 & 2.27 & 0.40 & 0.46 & - & $0.50^{* *}$ & $0.23^{*}$ & 0.17 & 0.17 \\
\hline 3. Mean attitude towards hobby items & 2.30 & 0.51 & 2.36 & 0.37 & 0.48 & & - & 0.10 & 0.11 & 0.16 \\
\hline 4. Attitude towards 'food' & 1.80 & 1.02 & 2.13 & 0.82 & - & & & - & $0.40^{* *}$ & -0.12 \\
\hline
\end{tabular}

${ }^{*}$ Differs significantly from zero, $p<0.05$.

** Differs significantly from zero, $p<0.01$.

Table 2

Means $(M)$, Standard deviations (SD), Cronbach's $\alpha$ and Pearson correlations $(r)$ between implicit and self-reported healthy versus unhealthy food attitudes and behaviour in overweight $(n=40)$ and normal-weight $(n=40)$ youngsters

\begin{tabular}{|c|c|c|c|c|c|c|c|c|c|c|}
\hline & \multicolumn{4}{|l|}{ Group } & \multirow[t]{3}{*}{$\alpha$} & \multirow[t]{3}{*}{2} & \multirow[t]{3}{*}{3} & \multirow[t]{3}{*}{4} & \multirow[t]{3}{*}{5} & \multirow[t]{3}{*}{6} \\
\hline & \multicolumn{2}{|c|}{ Overweight } & \multicolumn{2}{|c|}{ Normal-weight } & & & & & & \\
\hline & $M$ & SD & $M$ & SD & & & & & & \\
\hline 1. IAT-effect on the healthy/unhealthy food task & -259.72 & 162.71 & -291.90 & 181.45 & - & 0.02 & 0.03 & -0.04 & 0.16 & 0.09 \\
\hline 2. Mean attitude towards healthy food items & 2.38 & 0.61 & 2.31 & 0.46 & 0.70 & - & $0.58^{* *}$ & $0.39^{* *}$ & -0.05 & $-0.28^{*}$ \\
\hline 3. Mean attitude towards unhealthy food items & 2.39 & 0.55 & 2.35 & 0.44 & 0.69 & & - & $0.26^{*}$ & 0.02 & 0.04 \\
\hline 4. Attitude towards 'healthy food' & 1.82 & 1.32 & 1.95 & 0.96 & - & & & - & -0.04 & $-0.46^{* *}$ \\
\hline 5. Attitude towards 'unhealthy food' & 1.08 & 1.56 & 1.55 & 1.04 & - & & & & - & $0.36^{* *}$ \\
\hline 6. Attitude towards 'healthy versus unhealthy food' & -0.56 & 1.52 & -0.50 & 1.52 & - & & & & & - \\
\hline
\end{tabular}

${ }^{*}$ Differs significantly from zero, $p<0.05$.

** Differs significantly from zero, $p<0.01$.

same extent. Paired sample $t$-tests showed neither differences in the ratings of food and hobby, $t(79)=0.47$, ns, nor in the ratings of healthy and unhealthy food, $t(79)=0.43$, ns.

Further, no univariate group effects were found either on the attitude towards the categories food, $F(1,77)=$ 2.95 , ns, hobby, $F(1,77)=1.34$, ns, healthy food, $F(1,77)=0.62$, ns, and unhealthy food, $F(1,77)=2.53$, ns. This indicated that both groups were positive towards all four categories used in the respective IATs. Paired sample $t$-tests showed that the total group rated hobby more positive than food (hobby: $M=2.49, \mathrm{SD}=0.73$; food: $M=1.96, \quad \mathrm{SD}=0.93), \quad t(79)=5.06, \quad p<0.01, \eta^{2}=0.25$, and healthy food more positive than unhealthy food (healthy food: $M=1.89, \mathrm{SD}=1.14$; unhealthy food: $M=1.32, \mathrm{SD}=1.34), t(78)=2.82, p<0.01, \eta^{2}=0.09$.

Finally, no univariate group effects were found either on the relative attitude towards food versus hobby, $F(1$, $77)=0.39$, ns, and towards healthy food versus unhealthy food, $F(1,77)=2.26$, ns, indicating that both groups preferred their hobbies to food, and that they were neutral towards healthy versus unhealthy food. All means for the food and hobby attitudes are presented in Table 1, all means for the healthy and healthy food attitudes are reported in Table 2.

\subsection{Correlations between implicit and self-reported attitude measures}

All correlations concerning food and hobbies are presented in Table 1; all correlations concerning healthy and unhealthy food are presented in Table 2. Of particular interest were the Pearson correlations between the implicit and self-reported attitudes. No such correlations were found for food. However, for hobby, one significant negative correlation was found between the implicit attitude towards food versus hobby and the self-reported attitude towards hobby, $r=-0.27, p<0.05$, indicating that the more the youngsters implicitly preferred hobbies to food (negative IAT-score), the more they had a positive selfreported attitude towards a hobby.

Further, a significant positive correlation between the implicit attitude towards food versus hobby and the implicit attitude towards healthy versus unhealthy food was found, $r=0.36, p<0.01$, indicating that the more the youngsters implicitly preferred food to hobby, the more they implicitly preferred unhealthy food to healthy food, or that a preference for hobbies to food is related with a preference for healthy food to unhealthy food.

Also several correlations were found between the selfreported attitudes, both on the absolute versus the relative 
level as on the category versus the mean stimuli level. First, the attitude towards the hobby category correlated significantly with the relative attitude towards food versus hobby, $r=0.25, p<0.05$, indicating that a positive attitude towards hobbies, is related with a preference for hobbies to food. Further, the mean attitude towards the food items and the attitude towards the food category correlated significantly, $r=0.23, p<0.05$. The relative attitude towards healthy versus unhealthy food correlated significantly with the mean attitude towards the healthy food items, $r=$ $-0.28, p<0.05$, and with the attitude towards the healthy food category, $r=-0.46, p<0.01$, both indicating that the more the participants had a relative positive attitude towards healthy food, the more they had an absolute positive attitude towards healthy food. Also a significant correlation was found between the mean attitude towards the healthy food items and the attitude towards the healthy food category, $r=0.39, p<0.01$.

\section{Discussion}

This study aimed to extend the Craeynest et al. (2005) study, in which it was found that children with obesity implicitly like both unhealthy and healthy food, possibly indicating that they simply like eating. In contrast, normal-weight children reported positive attitudes towards healthy and unhealthy food on a self-report, but not on an implicit level. More specifically, this study investigated whether overweight youngsters would automatically prefer food when they had to choose between palatable food and hobbies, which they both strongly like on an explicit level. In order to test personal implicit attitudes instead of societal views (see Roefs \& Jansen, 2002), we used a personalized IAT with individually selected attractive stimuli. It was also examined whether a personalized IAT with idiosyncratic stimuli would reveal a stronger personal preference for palatable unhealthy food to palatable healthy food in overweight than in lean youngsters. Further, self-reported attitudes were assessed to examine whether the implicit attitudes correlated with the selfreported attitudes.

On the explicit level, no group differences were found. Both groups reported positive attitudes towards food in general, hobbies, healthy food and unhealthy food. The positive self-reported attitude towards healthy and unhealthy food in the overweight as well as in the lean group is in line with former studies (Craeynest et al., 2005; Roefs \& Jansen, 2002). Besides the mentioned possible bias of self-reports (Greenwald et al., 2002; see also Schwarz, 1999; Schwarz \& Oyserman, 2001), there are two alternative explanations for this finding: First, other attributes of food (such as taste) may be more salient for (dis)liking than being (un)healthy. Second, healthy and unhealthy behaviours are not necessarily two sides of the same coin, as people can like both apples and chocolate (see also Marshall, Biddle, Sallis, McKenzie, \& Conway, 2002), and the same may be true for food versus hobbies.
In contrast to our expectations, both personalized IATs did not reveal group differences. The food/hobby task indicated that both groups like food to the same amount as hobbies. The healthy/unhealthy food IAT revealed that overweight youngsters as well as lean controls implicitly prefer healthy food to unhealthy food, which is in contrast with the findings of Craeynest et al. (2005). One explanation may be that the overweight and the normal-weight group differed too small; therefore, it might be worthwhile to compare normal-weight youngsters with youngsters with obesity in future research.

The effect on the healthy/unhealthy food IAT, indicating that both groups preferred healthy food to unhealthy food, seems in line with the apple over candy preference in the study of Karpinski and Hilton (2001), which was explained in terms of societal instead of personal attitudes. This was unexpected because we used a personalized version of the IAT in which the more personal attribute labels 'I like versus I dislike' are used instead of the normative attribute labels 'positive versus negative' (Olson \& Fazio, 2004). In addition, we used personally selected attractive stimuli. However, the implicit healthy to unhealthy preference we found may still reflect a societal instead of a personal attitude because of two reasons. One reason may be that the labels of the target categories 'unhealthy versus healthy food' may carry a societal norm. Although we found positive correlations between the different kinds of self-reported attitudes, suggesting that the participants had at least the same self-reported attitude towards the IAT stimuli and category labels, some have argued that the IAT-effect depends mainly on the category labels than on the individual stimuli (De Houwer, 2001; but see Mitchell, Nosek, \& Banaji, 2003, Experiment 2). One possibility to avoid this problem, is to use less sensitive category labels to distinct healthy from unhealthy food (e.g., energy dense versus lean food). However, within the context of food choice in youngsters, it is important then to select labels covering the same nutritional content, and additionally, that these labels may be understood by children and youngsters. A second reason may be that the youngsters were primed by the strong distinction that was made between the healthy and the unhealthy food items lists from which they had to select the stimuli for the IAT. Possibly, the time between the explicit focus on the healthy and unhealthy food distinction and the performance on the IAT, has made it possible to activate societal views towards healthy and unhealthy food articles.

There may be several explanations why we did not obtain an IAT-effect on the food/hobby task. First, it may be due to a ceiling effect, because the food and hobby stimuli had to be selected under the condition of a very strong attractiveness. Consequently, it may be that the participants implicitly like the selected food and hobbies to the same degree. Second, it may be that overweight youngsters indeed prefer food to hobbies in contrast to normal weight controls, but that words are not strong enough to reveal this difference. The ecologic validity of pictures of palatable 
food may be stronger and therefore enhance the likelihood of an effect. Third, it may be possible that other processes than implicit food liking characterize overweight and obesity. For instance, it might be worthwhile to investigate to what extent the amount of (unhealthy) food or the activity of eating as such (e.g., the feeling of a filled mouth or stomach) play a role. Further, Berridge (1996; Berridge and Robinson, 2003) argues for two independent processes underlying food reward: On the one hand, eating may indeed be driven by liking or a positive attitude towards the taste of palatable food. On the other hand, the motivation to eat may also be guided by wanting, which may be considered as appetite or craving. According to Berridge, both processes can occur beyond the subject's awareness; therefore it may be assumed that they can be tapped using indirect measures. Assessing liking and wanting in alcohol addiction (according to the incentive sensitization theory of Robinson \& Berridge, 1993), Wiers et al. (2002) failed to find implicit alcohol preferences in heavy drinkers using a traditional IAT in which alcohol and soda had to be associated with positive and negative attributes. In contrast, they successfully assessed wanting using an IAT in which alcohol versus soda stimuli had to be associated with arousal versus passive words. Based on these and replicated findings (De Houwer, Crombez, Koster, \& De Beul, 2004), it is argued that alcohol addiction is determined by wanting rather than by liking. Within the context of obesity and weight control, several authors (Mela, 2001; Roefs, Herman, MacLeod, Smulders, \& Jansen, 2005) have suggested that overweight and obesity may especially be characterized by a stronger craving for food, as until now, no evidence for a stronger implicit food preference or liking has been found (Roefs \& Jansen, 2002; Roefs et al., 2005). Although behavioural evidence already exists that obesity is associated with impulsivity (Nederkoorn, Braet, Van Eijs, Tanghe, \& Jansen, 2006) and losing control (Hakala, Rissanen, Koskenvuo, Kaprio, \& Rönnemaa, 1999), it is worthwhile to investigate whether overweight and obesity are characterized by stronger implicit arousal associations towards unhealthy food, compared to lean controls.

Olson and Fazio (2004) found strong correlations of the personal implicit attitudes towards candy and apples with self-reported attitude measures. We only found significant correlations for hobby. Probably, the attitudes towards (unhealthy and healthy) food assessed in overweight youngsters are more social sensitive than their attitudes towards hobbies and than the attitudes towards candy and apples assessed in the normal-weight subjects of Olson and Fazio (2004).

This study has some limitations that should be considered. First, although both groups were tested in the same class context and at the same moment in time, it should be noted that implicit attitudes are not stable constructs, but that they may change in function of several conditions (Blair, 2002). Roefs et al. (2006, Experiment 1) found that a temporary change in attention focus ('imagine you work in a restaurant' versus 'focus on health'), determines whether palatable food was evaluated as tasty or unhealthy, independent of the participants' weight status. Therefore, further research on implicit attitude measurements should take this malleability more into account.

Second, as De Houwer (2002) noticed, the IAT can only provide a measure of the relative strength of associations, because at least two target concepts and two attribute concepts are needed. This could mean that it is in fact impossible to know whether the effect on the healthy/unhealthy food IAT was due to a preference for healthy food, or to a dislike for unhealthy food.

Finally, because the overweight group consisted only of a small number of youngsters with obesity, these findings could not be generalized to the obesity population. Perhaps, a replication of this study in a group of youngsters with obesity would reveal stronger results.

\section{Acknowledgements}

This research was supported by Grant B/03814/01 from Ghent University. We wish to thank Pol Craeynest, Tom Craeynest, and Kim Van Boxlaer for their help in collecting the data. Special thanks go to Jan De Houwer, Anne Roefs, and Ernst H.W. Koster for their useful advice and comments on the test construction.

\section{Appendix A. IAT stimuli}

\section{Attribute stimuli}

I like: holiday (vakantie), summer (zomer), sun (zon), smile (lach), love (liefde), and gift (geschenk).

I dislike: accident (ongeluk), war (oorlog), pain (pijn), dead (dood), disease (ziekte) and, divorce (scheiding).

\section{Target stimuli}

Palatable food: strawberries, banana, steak, crisps, chocolate, grapes, pan cakes, French fries, chicken, tomatoes, fish, yoghurt,...

Hobbies: book, computer game, dancing, bike, play station, sports, watching television, swimming, foot ball, movie, music, volley,...

Healthy food: strawberries, apple, grapes, fruit salad, turkey filet, chicken, cucumber, cherry, mango, peach, rice, soup,...

Unhealthy food: cake, chips, chocolate, croissant, coke, French fries, lasagne, sweets, pan cakes, pizza, steak,...

\section{References}

Berridge, K. C. (1996). Food reward: Brain substrates of wanting and liking. Neuroscience and Behavioral Reviews, 20, 1-25.

Berridge, K. C., \& Robinson, T. E. (2003). Parsing reward. Trends in Neurosciences, 26, 507-513.

Blair, I. (2002). The malleability of automatic stereotypes and prejudice. Personality and Social Psychology Review, 6, 242-261. 
Capaldi, E. D. (1996). Conditioned food preferences. In E. D. Capaldi (Ed.), Why we eat what we eat: The psychology of eating (pp. 53-80). Washington: American Psychological Association.

Cole, T. J., Bellizzi, M. C., Flegal, K. M., \& Dietz, W. H. (2000). Establishing a standard definition for child overweight and obesity worldwide: International survey. British Medical Journal, 320, 1-6.

Craeynest, M., Crombez, G., De Houwer, J., Deforche, B., Tanghe, A., \& De Bourdeaudhuij, I. (2005). Explicit and implicit attitudes towards food and physical activity in childhood obesity. Behaviour Research and Therapy, 43, 1111-1120.

De Clercq, A., Crombez, G., Buysse, A., \& Roeyers, H. (2003). A simple and sensitive method to measure timing accuracy. Behavior Research Methods, Instruments and Computers, 35, 109-115.

De Houwer, J. (2001). A structural and process analysis of the Implicit Association Test. Journal of Experimental Social Psychology, 37, 443-451.

De Houwer, J. (2002). The IAT as a tool for studying dysfunctional associations in psychopathology: Strengths and limitations. Journal of Behavior Therapy and Experimental Psychiatry, 33, 115-133.

De Houwer, J. (2003). The Extrinsic Affective Simon Task. Experimental Psychology, 50, 77-85.

De Houwer, J., Crombez, G., Koster, E. H. W., \& De Beul, N. (2004). Implicit alcohol-related cognitions in a clinical sample of heavy drinkers. Journal of Behavior Therapy and Experimental Psychiatry, 35, 275-286.

De Houwer, J., Custers, R., \& De Clercq, A. (2006). Do smokers have a negative implicit attitude towards smoking? Cognition and Emotion, 20, 1274-1284.

Dennison, C. M., \& Shepherd, R. (1995). Adolescent food choice: An application of the Theory of Planned Behaviour. Journal of Human Nutrition and Dietetics, 8, 9-23.

Dietz, W. H., \& Robinson, T. N. (2005). Overweight children and adolescents. The New England Journal of Medicine, 352, 2100-2109.

Drewnowski, A., Kurth, C., Holden-Wiltse, J., \& Saari, J. (1992). Food preferences in human obesity: Carbohydrates versus fats. Appetite, 18, 207-221.

Farooqi, I. S. (2005). Genetic and hereditary aspects of childhood obesity. Best Practice and Research Clinical Endocrinology and Metabolism, 19, 359-374.

Fazio, R. H. (1990). Multiple processes by which attitudes guide behaviour: The MODE model as an integrative framework. Advances in Experimental Social Psychology, 23, 75-109.

Fazio, R. H., \& Olson, M. A. (2003). Implicit measures in social cognition research: Their meaning and use. Annual Review of Psychology, 54, 297-327.

Fox, K. R. (2004). Childhood obesity and the role of physical activity. Journal of the Royal Society for the Promotion of Health, 124, 34-39.

Greenwald, A. G., Banaji, M. R., Rudman, L. A., Farnham, S. D., Nosek, B. A., \& Mellot, D. S. (2002). A unified theory of implicit attitudes, stereotypes, self-esteem, and self-concept. Psychological Review, 109, $3-25$.

Greenwald, A. G., McGhee, D. E., \& Schwartz, J. L. (1998). Measuring individual differences in implicit cognition: The Implicit Association Test. Journal of Personality and Social Psychology, 74, 1464-1480.

Greenwald, A. G., Nosek, B. A., \& Banaji, M. R. (2003). Understanding and using the Implicit Association Test: An improved scoring algorithm. Journal of Personality and Social Psychology, 85, 197-216.

Haerens, L., Deforche, B., Maes, L., Stevens, V., Cardon, G., \& De Bourdeaudhuij, I. (2006). Body mass effects of a physical activity and healthy food intervention in middle schools. Obesity research, 14, 847-854.

Hakala, P., Rissanen, A., Koskenvuo, M., Kaprio, J., \& Rönnemaa, T. (1999). Environmental factors in the development of obesity in identical twins. International Journal of Obesity, 23, 746-753.

Hermans, D., \& De Houwer, J. (1994). Affective and subjective familiarity ratings of 740 Dutch words. Psychologica Belgica, 34, 115-139.
Karpinski, A., \& Hilton, J. L. (2001). Attitudes and the Implicit Association Test. Journal of Personality and Social Psychology, 81, 774-788.

Lissau, I., Overpeck, M. D., Ruan, W. J., Due, P., Holstein, B. E., \& Hediger, M. L. (2004). Body mass index and overweight in adolescents in 13 European countries, Israel, and the United States. Archives of Pediatrics and Adolescent Medicine, 158, 27-33.

Marshall, S. J., Biddle, S. J. H., Sallis, J. F., McKenzie, T. L., \& Conway, T. L. (2002). Clustering of sedentary behaviours and physical activity among youth: A cross-national study. Pediatric Exercise Science, 14, 401-417.

McGloin, A. F., Livingstone, M. B. E., Greene, L. C., Webb, S. E., Gibson, J. M. A., Jebb, S. A., et al. (2002). Energy and fat intake in obese children and lean children at varying risk of obesity. International Journal of Obesity, 26, 200-207.

Mela, D. J. (2001). Determinants of food choice: Relationships with obesity and weight control. Obesity Research, 9, 249S-255S.

Mitchell, J. P., Nosek, B. A., \& Banaji, M. R. (2003). Contextual variations in implicit evaluation. Journal of Experimental Psychology: General, 132, 455-469.

Nederkoorn, C., Braet, C., Van Eijs, Y., Tanghe, A., \& Jansen, A. (2006). Why obese children can not resist food: The role of impulsivity. Eating Behaviors, 7, 315-322.

Nicklas, T. A., Yang, S.-J., Baranowski, T., Zakeri, I., \& Berenson, G. (2003). Eating patterns and obesity in children. The Bogalusa Heart Study. American Journal of Preventive Medicine, 25, 9-16.

Olson, M. A., \& Fazio, R. H. (2004). Reducing the influence of extrapersonal associations on the Implicit Association Test: Personalizing the IAT. Journal of Personality and Social Psychology, 86, 653-667.

Perl, M. A., Mandic, M. L., Primorac, L., Klapec, T., \& Perl, A. (1998). Adolescent acceptance of different foods by obesity status and by sex. Physiology and Behaviour, 65, 241-245.

Reed, D. R., Bachmanov, A. A., Beauchamp, G. K., Tordoff, M. G., \& Price, A. R. (1997). Heritable variation in food preferences and their contribution to obesity. Behavior Genetics, 27, 373-387.

Robinson, T. E., \& Berridge, K. C. (1993). The neural basis of drug craving: An incentive-sensitization theory of addiction. Brain Research Reviews, 18, 247-291.

Roefs, A., Herman, C. P., MacLeod, C. M., Smulders, F. T. Y., \& Jansen, A. (2005). At first sight: How do restrained eaters evaluate high-fat palatable foods? Appetite, 44, 103-114.

Roefs, A., \& Jansen, A. (2002). Implicit and explicit attitudes toward highfat foods in obesity. Journal of Abnormal Psychology, 111, 517-521.

Roefs, A., Quaedackers, L., Werrij, M. Q., Wolters, G., Havermans, R., Nederkoorn, C., et al. (2006). The environment influences whether high-fat foods are associated with palatable or with unhealthy. Behaviour Research and Therapy, 44, 715-736.

Schwartz, M. B., Chen, E. Y., \& Brownell, K. D. (2003). Trick, treat, or toy: Children are just as likely to choose toys and candy on Halloween. Journal of Nutrition Education and Behavior, 35, 207-209.

Schwarz, N. (1999). Self-reports. How the questions shape the answers. American Psychologist, 54, 93-105.

Schwarz, N., \& Oyserman, D. (2001). Asking questions about behaviour: Cognition, communication, and questionnaire construction. American Journal of Evaluation, 22, 127-160.

Swanson, J. E., Rudman, L. A., \& Greenwald, A. G. (2001). Using the Implicit Association Test to investigate attitude-behaviour consistency for stigmatised behaviour. Cognition and Emotion, 15, 207-230.

Valverde, M. A., Patin, R. V., Oliveira, F. L. C., Lopez, F. A., \& Vitolo, M. R. (1998). Outcomes of obese children and adolescents enrolled in a multidisciplinary health program. International Journal of Obesity, 22, 513-519.

Wiers, R. W., van Woerden, N., Smulders, F. T. Y., \& Jong, P. J. (2002). Implicit and explicit alcohol-related cognitions in heavy and light drinkers. Journal of Abnormal Psychology, 111, 648-658. 